\title{
Sida tuberculata (Malvaceae): a study based on development of extractive system and in silico and in vitro properties
}

\author{
H.S. da Rosa ${ }^{1,2,3}$, A.C.F. Salgueiro ${ }^{1,3}$, A.Z.C. Colpo ${ }^{1,3}$, F.R. Paula ${ }^{2}$, A.S.L. Mendez $z^{3,4}$ \\ and V. Folmer ${ }^{1,3}$ \\ ${ }^{1}$ Laboratório de Bioquímica e Toxicologia de Produtos Naturais e Sintéticos, Universidade Federal do Pampa \\ Uruguaiana, RS, Brasil \\ ${ }^{2}$ Laboratório de Desenvolvimento e Controle de Qualidade em Medicamentos, Universidade Federal do Pampa \\ Uruguaiana, RS, Brasil \\ ${ }^{3}$ Programa de Pós-Graduação em Bioquímica, Universidade Federal do Pampa, Uruguaiana, RS, Brasil \\ ${ }^{4}$ Faculdade de Farmácia, Universidade Federal do Rio Grande do Sul, Porto Alegre, RS, Brasil
}

\begin{abstract}
Sida tuberculata (Malvaceae) is a medicinal plant traditionally used in Brazil as an antimicrobial and anti-inflammatory agent. Here, we aimed to investigate the different extractive techniques on phytochemical parameters, as well as to evaluate the toxicity and antioxidant capacity of $S$. tuberculata extracts using in silico and in vitro models. Therefore, in order to determine the dry residue content and the main compound 20-hydroxyecdysone (20E) concentration, extracts from leaves and roots were prepared testing ethanol and water in different proportions. Extracts were then assessed by Artemia salina lethality test, and toxicity prediction of 20E was estimated. Antioxidant activity was performed by DPPH and ABTS radical scavenger assays, ferric reducing power assay, nitrogen derivative scavenger, deoxyribose degradation, and TBARS assays. HPLC evaluation detected 20E as main compound in leaves and roots. Percolation method showed the highest concentrations of $20 \mathrm{E}$ ( 0.134 and $0.096 \mathrm{mg} / \mathrm{mL}$ of extract for leaves and roots, respectively). All crude extracts presented low toxic potential on $A$. salina $\left(\mathrm{LD}_{50}>1000 \mu \mathrm{g} / \mathrm{mL}\right)$. The computational evaluation of $20 \mathrm{E}$ showed a low toxicity prediction. For in vitro antioxidant tests, hydroethanolic extracts of leaves were most effective compared to roots. In addition, hydroethanolic extracts presented a higher $\mathrm{IC}_{50}$ antioxidant than aqueous extracts. TBARS formation was prevented by leaves hydroethanolic extract from 0.015 and $0.03 \mathrm{mg} / \mathrm{mL}$ and for roots from 0.03 and $0.3 \mathrm{mg} / \mathrm{mL}$ on egg yolk and rat tissue, respectively $(\mathrm{P}<0.05)$. These findings suggest that $S$. tuberculata extracts are a considerable source of ecdysteroids and possesses a significant antioxidant property with low toxic potential.
\end{abstract}

Key words: Sida tuberculata; 20-hydroxyecdysone; Toxicity prediction; Antioxidant

\section{Introduction}

Sida species are widespread around the world, occurring predominantly in the tropics, particularly in South America. Some species of this genus has been employed in traditional medicine for a long time, such as $S$. rhombifolia, $S$. acuta and $S$. cordifolia $(1,2)$. In Brazil, Sida species are used in folk medicine for treatment of stomatitis, blenorrhea, asthmatic bronchitis and other inflammatory processes $(3,4)$. Among the several species of this genus is $S$. tuberculata (Malvaceae), a medicinal plant widely distributed in South Brazil. Traditionally, leaves and roots of this species have been used as anti-inflammatory, hypoglycemic and antimicrobial agents.
Previous studies with different extracts and isolated compounds of this genus have described important biologic effects. Aqueous extracts from $S$. cordifolia reduced the damage caused by rotenone and presented a therapeutic action in Parkinson's disease (5). S. acuta revealed a significant hepatoprotective effect against liver damage induced by paracetamol overdose (6). Leaf extracts of S. rhomboidea demonstrated a significant cardiovascular protective effect (7). The anti-inflammatory activity also was investigated for $S$. tiagii extracts, which presented similar results to the standard drugs tested (8). Our group previously found a significant antimicrobial effect of $S$. tuberculata extracts against $C$. krusei strain (9). 
Chemical investigations of Sida spp. have indicated the presence of a wide variety of compounds. Among the main classes of chemicals detected, ecdysteroids (10), alkaloids (11) and flavonoids (12) are predominant. Within the ecdysteroids class, polyhydroxylated ketosteroids and its derivatives are the most frequent $(13,14)$. Ecdysteroids are produced primarily in arthropods and plants, but are also present in fungi, and even in marine sponges (15). Interesting observations on the potential importance of ecdysteroids have justified studies on function and biological properties of this class.

Recently, our research group identified, among others, 20-hydroxyecdysone (20E), a major ecdysteroid in $S$. tuberculata, as well as flavonoids and alkaloids (9). Thus, considering our interest about $S$. tuberculata biological properties, in the current work, different extracts were evaluated based on phytochemical parameters and assessed for their toxicological and antioxidant potential.

\section{Material and Methods}

\section{Plant material}

The whole plant was collected in Uruguaiana (Rio Grande do Sul, Brazil), a city located at the western border with Argentina. A specimen was identified and a voucher (Sida tuberculata R.E. Fries; ICN 167493) was deposited at ICN Herbarium (Instituto de Biociências, Universidade Federal do Rio Grande do Sul, Brazil).

\section{Extract obtainment}

Initially, the plant was separated into leaves and roots. Each material was submitted to drying at $40^{\circ} \mathrm{C}$, reduced to a powder and submitted to extraction by maceration, reflux, and percolation techniques. Aiming to evaluate the most adequate system, three ethanol concentrations were tested on extraction: 20,30 and $40 \%(\mathrm{v} / \mathrm{v}$ ) for leaves and 50,70 and $90 \%(\mathrm{v} / \mathrm{v})$ for roots. This choice was based on the plant's tissue rigidity. In all cases, the plant:solvent proportion was standardized at 1:10 (w/v). Aqueous infusions (tea) were also prepared for toxicity and antioxidant assays according to methodologies described below.

\section{Dry residue determination}

Dry residue assay was performed according to Brazilian Pharmacopoeia (16). Briefly, $2.0 \mathrm{~mL}$ of each extract were submitted to drying at $105^{\circ} \mathrm{C}$ until a residual mass correspondent to the concentration of dried extractives was obtained. All developed extracts were assayed in triplicate.

\section{Chromatographic analysis}

Extract samples were evaluated by a high performance liquid chromatograph coupled with diode array detection (HPLC-DAD) (9). Chromatography analysis was performed with a Prominence liquid chromatograph (Shimadzu, Japan), equipped with a binary pump LC-20AD with SIL10AF auto sampler and SPDM10A PDA detector. Mobile phase consisted of (A) $0.05 \%$ phosphoric acid in water and (B) acetonitrile, prepared daily, filtered through a $0.45-\mathrm{mm}$ membrane filter (Millipore, Germany) and sonicated before use. The separation was accomplished using a Phenomenex Luna C-18(2) column $(250 \times 4.6 \mathrm{~mm}, 5 \mu \mathrm{m})$ with a gradient elution protocol of $0.01-23 \mathrm{~min}, 10-40 \%$ solvent B; $23.01-40 \mathrm{~min}, 10 \%$ solvent $\mathrm{B}$, at a flow rate of $0.8 \mathrm{~mL} /$ min. Injection volume was $20 \mu \mathrm{L}$ and DAD detector was operated at $250 \mathrm{~nm}$.

20-hydroxyecdysone monitoring. Aiming to determine the concentration of the major compound $20 \mathrm{E}$ in extract, five concentrations $(10,50,100,200$ and $500 \mu \mathrm{g} / \mathrm{mL})$ of standard solution (20E, Sigma Aldrich, USA, 93\% purity) were prepared in methanol. Chromatographic injections were made in triplicate. All solutions were freshly prepared and filtered through a $0.45-\mathrm{mm}$ membrane filter (Millipore), prior to analysis.

\section{Computational prediction}

Aiming to identify possible nutraceuticals, we evaluated the predictive toxicity of $20 \mathrm{E}$. For this, we analyzed the risks of damages, such as genotoxic damage, endocrine disruption, irritation and hERG (the human ether-à-go-go-related gene) inhibition. Data were generated on-line using ADME-Tox web server software, Advanced Chemistry Development, Inc. (ACD/Labs, ACD/Percepta Platform, version 12.01, Canada, www. acdlabs.com, 2013) (17), which predicts the fragments that could lead to possible toxic effects.

In addition, the $20 \mathrm{E}$ was subjected to the drug-likeness evaluation and drug-score profiles using the Osiris Property Explorer program available on the web [http:// www.organic-chemistry.org/prog/peo] (18), comparing it with a reference substance.

\section{Artemia salina assay}

Based in dry residue and HPLC analysis, we selected extracts (ethanol 70 and $40 \%$ for roots and leaves, respectively) to be used in this test. Extracts were concentrated and ethanol was evaporated.

The test was performed according to Meyer et al. (19) with minor modifications. Briefly, $A$. salina eggs were incubated in seawater with $3 \% \mathrm{NaCl}$ at room temperature for $24 \mathrm{~h}$. After, A. saline larvae (10 approximately) were transferred to ELISA plate wells containing different extract concentrations $(100-1000 \mu \mathrm{g} / \mathrm{mL})$ prepared by diluting the extract in $10 \mathrm{~mL}$ of the artificial saline solution. For control, larvae were incubated with seawater only. Plates were maintained at $28 \pm 1^{\circ} \mathrm{C}$ for $24 \mathrm{~h}$ and the survival rate (\%) was counted for lethal dose $50 \%\left(L_{50}\right)$ determination. Three independent experiments were performed.

\section{Determination of antioxidant capacity}

For antioxidant activity protocols, solutions obtained by percolation with ethanol 70 and $40 \%$ for roots and leaves, respectively, were selected. The aqueous extracts were also 
evaluated with these protocols. For all assays described below, the samples were diluted to obtain a concentration range of $0.003-0.3 \mathrm{mg} / \mathrm{mL}$. It is important to emphasize that the color controls were used for all extracts, avoiding probable interference of extracts color in results. Moreover, except for thiobarbituric acid reactive substances (TBARS) protocols in animal tissue, results are expressed in half maximal inhibitory concentration $\left(\mathrm{IC}_{50}\right)$.

$\mathrm{DPPH}^{\circ}$ assay. Antiradical activity of $S$. tuberculata extracts was determined using the $\mathrm{DPPH}^{\bullet}$ method (20). Different concentrations of extracts were added to DPPH ${ }^{\bullet}$ solution. After $30 \mathrm{~min}$ of incubation at room temperature, the reduction in the number of free radicals was measured by reading the absorbance at $517 \mathrm{~nm}$. Values are reported in $\mathrm{IC}_{50}$ based on percentage of inhibition of DPPH ${ }^{\bullet}$ absorbance in relation to the control values without extracts.

$\mathrm{ABTS}^{\bullet+}$ scavenger activity. $\mathrm{ABTS}^{\bullet+}$ radical cation (21) was obtained by the reaction between the ABTS solution with the $\mathrm{K}_{2} \mathrm{~S}_{2} \mathrm{O}_{8}(140 \mathrm{mM})$ solution for $12-16 \mathrm{~h}$ in the dark at room temperature. Antioxidant assay was performed by incubation of extract samples and $\mathrm{ABTS}^{\bullet+}$ (final volume of $1.5 \mathrm{~mL}$ ) during $6 \mathrm{~min}$ in the dark. The absorbance was measured at $734 \mathrm{~nm}$. Ethyl alcohol was used as blank to calibrate the spectrophotometer.

Ferric reducing potential assay (FRAP). The ferric reducing power of $S$. tuberculata extracts was determined using a modified version of the FRAP assay (based on the chemical reduction of $\mathrm{Fe}^{3+}$ to $\mathrm{Fe}^{2+}$ ) (22). Briefly, aliquots of the extract were added to freshly prepared and prewarmed $\left(37^{\circ} \mathrm{C}\right)$ FRAP reagent and incubated at $37^{\circ} \mathrm{C}$ for $30 \mathrm{~min}$. Reduction was monitored by measuring the change of absorbance at $593 \mathrm{~nm}$.

Nitrogen derivative species scavenging activity. According to Marcocci et al. (23), the assay is based on the reaction of nitric oxide radical $\left(\mathrm{NO}^{\circ}\right)$ produced by sodium nitroprusside in aqueous solution at physiological $\mathrm{pH} 7.2$. Under aerobic conditions, $\mathrm{NO}^{\bullet}$ reacts with oxygen to produce nitrogen derivative products (i.e., nitrate and nitrite) which can be determined using Griess reagent. Values report the percentage of nitrite reaction inhibition with Griess reagent depicted by the $S$. tuberculata extracts as an index of the $\mathrm{NO}^{\bullet}$ scavenging activity.

Deoxyribose assay. This assay was performed in accordance with modifications proposed by Puntel et al. (24). Here, hydroxyl radicals were generated by Fenton reaction. Antioxidant capacity was evaluated by the extract's ability to neutralize hydroxyl radicals. Results are reported in $\mathrm{IC}_{50}$ based on percentage of inhibition.

Lipid peroxidation assay. Using egg-yolk homogenates, a modified TBARS protocol was employed to measure the formed lipid peroxide (25). Briefly, egg yolk was homogenized and mixed with $S$. tuberculata extracts and $\mathrm{FeSO}_{4}$. This mixture was incubated at $37^{\circ} \mathrm{C}$ for $60 \mathrm{~min}$, and used in the TBARS assay. Values are reported in equivalents of malondialdehyde (MDA) generated by lipid peroxidation and corrected by $\mathrm{mg}$ of tissue.
TBARS in brain and liver of rats. A total of 4 adult male rats (Wistar) were maintained and used in accordance with guidelines of the Committee on Care and Use of Experimental Animal Resources (Protocol approved \#001/ 2012, UNIPAMPA). The animals were sacrificed by decapitation and the brain and liver were removed, quickly homogenized in $\mathrm{NaCl}(150 \mathrm{mM})$ and kept on ice. TBARS content was determined as described by Ohkawa et al. (26), using a standard curve of MDA. Briefly, after homogenization, samples were centrifuged at $4000 \mathrm{~g}$ at $4^{\circ} \mathrm{C}$ for $10 \mathrm{~min}$ to yield a low speed supernatant fraction (S1). The obtained S1 was used for basal and/or prooxidants $\left(\mathrm{FeSO}_{4}\right)$ induced lipid peroxidation. This mixture was incubated at $37^{\circ} \mathrm{C}$ for $60 \mathrm{~min}$, and after used in the TBARS assay. Values are reported in nmol of MDA generated by lipid peroxidation and corrected by protein content.

\section{Statistical analysis}

Data are reported as means $\pm S D$ for at least three independent determinations for each experimental step. Statistical differences between groups were determined by two-way ANOVA with the Tukey's post tests. Values of $\mathrm{P} \leqslant 0.05$ were considered the limit for significance.

\section{Results}

\section{Dry residue}

Results obtained from dry residue assay are described in Table 1. The higher yield of dry content occurred when the extracts were prepared by percolation. In terms of alcoholic concentration, the most efficient solvents were hydroethanolic solutions at $40 \%$ for leaves and at $70 \%$ for roots, when the dry residue parameter was considered alone.

Table 1. Results obtained from dry residue assay for hydroethanolic extracts of $S$. tuberculata prepared using different extraction techniques.

\begin{tabular}{llll}
\hline Solvent & \multicolumn{3}{c}{ Dry residue (\% w/w) } \\
\cline { 2 - 4 } & \multicolumn{3}{c}{ Extraction technique } \\
\cline { 2 - 4 } & Maceration & Percolation & Reflux \\
\hline Leaves & & & \\
Ethanol $20 \%$ & $1.42(1.5 \%)$ & $1.84(0.49 \%)$ & $1.92(2.0 \%)$ \\
Ethanol 40\% & $1.44(4.4 \%)$ & $2.88(0.32 \%)$ & $2.17(1.0 \%)$ \\
Ethanol 70\% & $1.20(2.9 \%)$ & $1.75(4.73 \%)$ & $1.79(2.4 \%)$ \\
Roots & & & \\
Ethanol 50\% & $1.21(1.4 \%)$ & $2.00(1.5 \%)$ & $1.24(4.9 \%)$ \\
Ethanol 70\% & $1.34(0.6 \%)$ & $2.93(4.3 \%)$ & $1.26(2.1 \%)$ \\
Ethanol 90\% & $1.03(0.1 \%)$ & $0.91(3.0 \%)$ & $1.26(3.9 \%)$ \\
\hline
\end{tabular}

Data are reported as the average of three analyses and relative standard deviation (RSD, \% w/w). 


\section{Chromatographic analysis}

HPLC analyses were performed evaluating $S$. tuberculata extracts obtained from maceration, percolation and reflux. In leaves, two major peaks were identified, with retention times $(\mathrm{Rt})$ of approximately 17.2 (peak 1) and 18.0 min (peak 2). The most representative ecdysteroid (20E) present in the leaves (peak 1) was also accompanied by significant amounts of another phenolic compound, a kaempferol derivative (peak 2). In roots, $20 \mathrm{E}$ was detected as the major compound.
In order to evaluate extraction efficiencies, the peak areas of $20 \mathrm{E}$ were considered. Data showed that percolation was the most effective technique followed by reflux and maceration (Figure 1). In addition, results revealed that $20 \mathrm{E}$ concentration was greater in leaves than roots extracts, 0.134 and $0.096 \mathrm{mg} / \mathrm{mL}$, respectively (Table 2).

\section{In silico predictions}

The 20E compound was submitted to computational prediction of toxic effects using ACD/Labs. This effect was

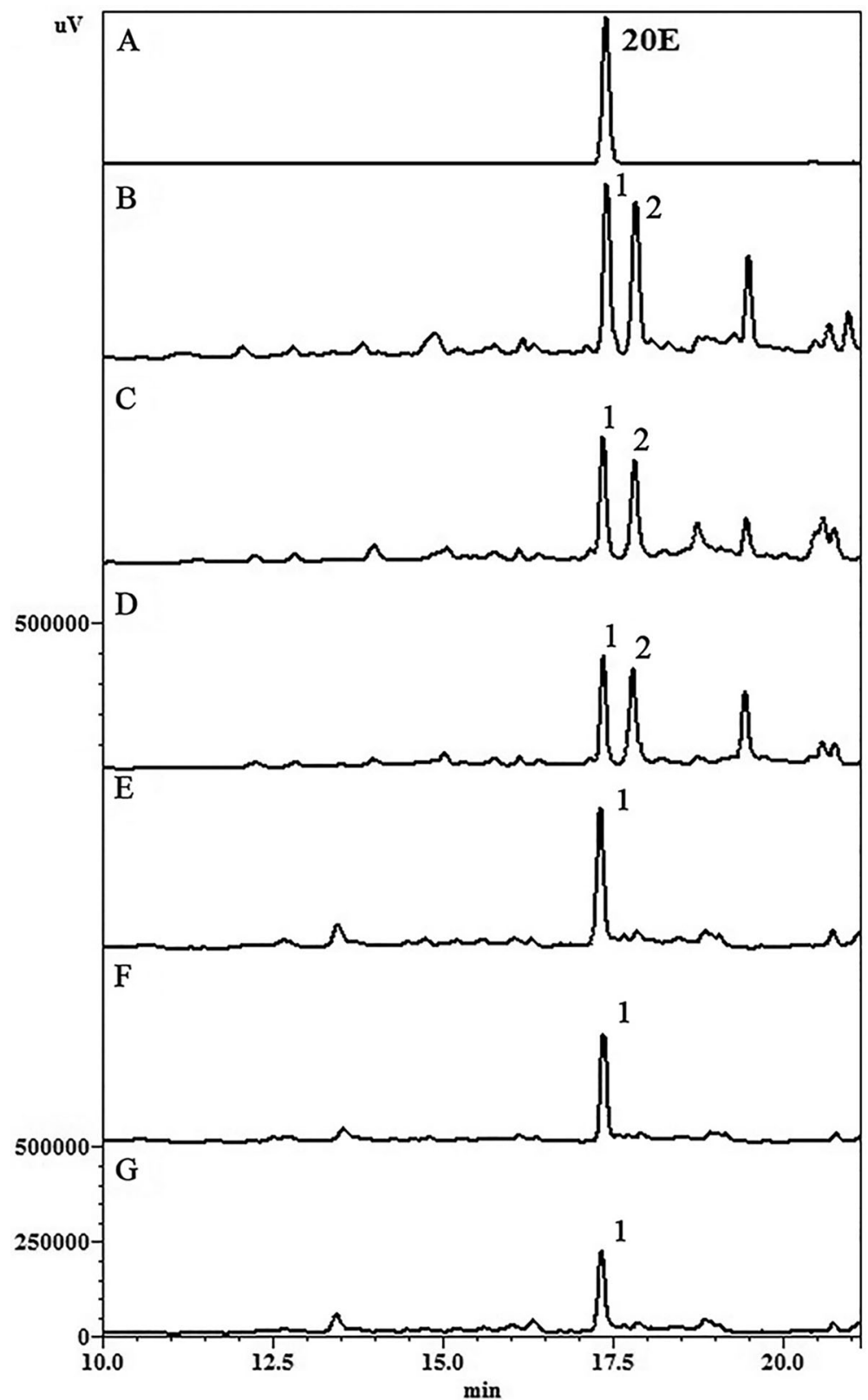

Figure 1. Comparative chromatogram of $S$. tuberculata extracts, using $40 \%$ ethanol for leaves and $70 \%$ ethanol for roots. $A$, reference substance of $100 \mu \mathrm{g} / \mathrm{mL}$ 20-hydroxyecdysone (20E). B, C, and $D$, leaf hydroethanolic extract obtained by percolation, reflux and maceration, respectively. $E, F$, and $G$, root hydroethanolic extract obtained by percolation, reflux and maceration, respectively. Peak 1: 20E, Peak 2: Kaempferol derivative, acquired at $250 \mathrm{~nm}$. 
evaluated by the probability of producing a positive Ames Test outcome (Ames test against Salmonella typhimurium TA97a, TA98, TA100, TA102, TA104, TA1535, TA1537 and TA1538), a positive endocrine disruptor test outcome, hERG inhibition and irritant effects. 20E showed a low probability to cause toxic effects in all the parameters evaluated (Table 3 ). Thus, these data suggest that 20E may be non-genotoxic, non-reproductive-system toxic, non-cardiotoxic and nonirritant. The software also predicted that $20 \mathrm{E}$ does not present hazardous fragments, which are interconnected with mutagenic effects.

The Osiris Property Explorer calculated the druglikeness and drug-score characteristics based in the list of all available fragments from 3300 traded drugs as well as 15,000 commercially available chemicals (Fluka, Germany). In this work, Osiris results showed that $20 \mathrm{E}$ had a positive drug-likeness (0.62) and drug-score (0.2) values (Table 4$)$. The $20 \mathrm{E}$ values were greater than those of $\alpha$-tocopherol (-6.2 drug-likeness; 0.11 drug-score, respectively), and greater than drug-likeness of ascorbic acid (0.02).

Table 2. 20-hydroxyecdysone concentration in S. tuberculata hydroethanolic extracts using different extraction techniques.

\begin{tabular}{lccc}
\hline Solvent & \multicolumn{2}{c}{ 20-hydroxyecdysone $(\mathrm{mg} / \mathrm{mL}$ of extract) } \\
\cline { 2 - 4 } & \multicolumn{3}{c}{ Extraction technique } \\
\cline { 2 - 4 } & Maceration & Percolation & Reflux \\
\hline Leaves & & & \\
Ethanol $20 \%$ & $0.073(3.1 \%)$ & $0.087(1.7 \%)$ & $0.089(1.8 \%)$ \\
Ethanol $40 \%$ & $0.074(4.8 \%)$ & $0.134(3.0 \%)$ & $0.101(1.7 \%)$ \\
Ethanol $70 \%$ & $0.062(3.8 \%)$ & $0.081(2.7 \%)$ & $0.083(2.0 \%)$ \\
Roots & & & \\
Ethanol $50 \%$ & $0.045(3.1 \%)$ & $0.065(2.3 \%)$ & $0.059(3.3 \%)$ \\
Ethanol 70\% & $0.050(4.4 \%)$ & $0.096(3.4 \%)$ & $0.060(3.5 \%)$ \\
Ethanol 90\% & $0.038(2.2 \%)$ & $0.030(2.9 \%)$ & $0.060(2.7 \%)$ \\
\hline
\end{tabular}

Data are reported as the average of three analyses and relative standard deviation (RSD, \%).

Table 3. In-silico screening using toxicity predictions for 20hydroxyecdysone compound present in S. tuberculata extracts.

\begin{tabular}{lcc}
\hline Toxicity modules & Probability $^{*}$ & Toxicity risk \\
\hline Genotoxic (Ames test) & 0.10 & $(+)$ \\
Estrogen receptor alpha binding & 0.01 & $(+)$ \\
Irritant & 0.00 & $\mathrm{ND}$ \\
hERG inhibitor & 0.03 & $(+)$ \\
\hline
\end{tabular}

*Probability of causing toxic effects. The scale of toxicity risk ranges from low $(+)$, medium $(++)$, to high $(+++)$ and not detected (ND) calculated by using ACD/Labs program.

\section{Artemia salina toxicity}

Results of $A$. salina toxicity are shown in Table 5 . $S$. tuberculata presented low toxicity to $A$. salina larvae $\left(L_{50}>1000 \mu \mathrm{g} / \mathrm{mL}\right)$ for both leaves and roots extracts.

\section{Antioxidant assays}

In the DPPH ${ }^{\bullet}$ assay, the hydroethanolic extracts from leaves showed the most effective result with $\mathrm{IC}_{50}$ activity at $0.116 \mathrm{mg} / \mathrm{mL}$ followed by hydroethanolic root with $\mathrm{IC}_{50}$ of $0.142 \mathrm{mg} / \mathrm{mL}$ (Table 6 ). Aqueous extracts showed the lowest antioxidant capacity.

In the ABTS. ${ }^{+}$assay, $\mathrm{IC}_{50}$ values ranged from 0.014 (hydroethanolic leaf) to $0.545 \mathrm{mg} / \mathrm{mL}$ (aqueous root). Compared to DPPH ${ }^{\bullet}$ assay, hydroethanolic leaves had the highest potential scavenger, approximately 10-fold. In addition, hydroethanolic leaf extract possessed the highest $\mathrm{ABTS}^{\bullet+}$ inhibition followed by root extract.

In the FRAP protocol, the oxidative form of iron $\left(\mathrm{Fe}^{+3}\right)$ is converted to ferrous $\left(\mathrm{Fe}^{+2}\right)$ by antioxidant compounds. Extracts of $S$. tuberculata expressed great reducing activity. As shown in Table 6, hydroethanolic leaf extract had the most pronounced effect of all assessed protocols $\left(\mathrm{IC}_{50}=0.006 \mathrm{mg} / \mathrm{mL}\right)$. Similarly, aqueous extracts of leaves were also potent in FRAP activity $\left(\mathrm{IC}_{50}=0.011 \mathrm{mg} / \mathrm{mL}\right)$.

The nitrogen reactive species scavenger test illustrates percentage inhibition of nitrogen reactive species by extracts from leaves and roots of $S$. tuberculata. The $I_{50}$ value of hydroethanolic and aqueous extracts ranged from 0.118 and $0.996 \mathrm{mg} / \mathrm{mL}$ (Table 6). Both extracts, leaves and roots, showed a significant $(P<0.05)$ scavenging

Table 4. Values of drug-likeness and drug-score for 20hydroxyecdysone (20E) and reference antioxidant compounds ( $\alpha$-tocopherol and ascorbic acid) by the Osiris Property Explorer program.

\begin{tabular}{lccc}
\hline & $20 \mathrm{E}$ & $\alpha$-tocopherol & Ascorbic acid \\
\hline Drug-likeness & 0.62 & -6.27 & 0.02 \\
Drug-score & 0.20 & 0.11 & 0.74 \\
\hline
\end{tabular}

Osiris Property Explorer program < http://www.organicchemistry. org/prog/peo/>

Table 5. Values of $50 \%$ lethal dose $\left(\mathrm{LD}_{50}\right)$ obtained from Artemia salina assay to $S$. tuberculata extracts.

\begin{tabular}{lll}
\hline Plant extract & \multicolumn{2}{c}{$\mathrm{LD}_{50}(\mu \mathrm{g} / \mathrm{mL})$} \\
\cline { 2 - 3 } & Hydroethanolic & Aqueous \\
\hline Leaves & $>1000(3.1 \%)$ & $>1000(2.8 \%)$ \\
Roots & $>1000(4.0 \%)$ & $>1000(4.9 \%)$ \\
\hline
\end{tabular}

Data are reported as the average of three analyses and relative standard deviation (RSD). 
Table 6. Maximal inhibitory concentration $\left(\mathrm{IC}_{50}\right)$ values of antioxidant assays from different extracts of S. tuberculata.

\begin{tabular}{|c|c|c|c|c|}
\hline \multirow[t]{3}{*}{ Assays } & \multicolumn{4}{|c|}{$\mathrm{IC}_{50}(\mathrm{mg} / \mathrm{mL})$} \\
\hline & \multicolumn{2}{|c|}{ Leaves extract } & \multicolumn{2}{|c|}{ Roots extract } \\
\hline & Hydroethanolic & Aqueous & Hydroethanolic & Aqueous \\
\hline DPPH & $0.116 \pm 0.88^{*}$ & $0.470 \pm 0.68$ & $0.142 \pm 1.02^{*}$ & $0.401 \pm 0.98^{\#}$ \\
\hline ABTS & $0.014 \pm 0.02^{*}$ & $0.115 \pm 0.01^{\#}$ & $0.058 \pm 0.01^{*}$ & $0.545 \pm 0.04$ \\
\hline FRAP & $0.006 \pm 0.003^{\#}$ & $0.011 \pm 0.07^{\#}$ & $0.109 \pm 0.014$ & $0.129 \pm 0.028$ \\
\hline NO scavenger & $0.118 \pm 2.06^{\star \#}$ & $0.248 \pm 2.77^{\#}$ & $0.272 \pm 1.04^{*}$ & $0.996 \pm 2.61$ \\
\hline Deoxyribose assay & $0.012 \pm 1.61^{*}$ & $0.029 \pm 0.85^{\#}$ & $0.013 \pm 0.81^{*}$ & $0.259 \pm 1.36$ \\
\hline
\end{tabular}

Data are reported as mean $\pm S D$ for $n=3 .{ }^{*} P<0.05$ between the hydroethanolic and aqueous solvents in the same extract. ${ }^{\#} \mathrm{P}<0.05$ differences within the same solvent between leaves and roots (ANOVA with Tukey's post-test).

activity. However, extracts of leaves had more scavenger property than root extracts.

In deoxyribose degradation assays, extracts presented a potent scavenger activity of hydroxyl radical, one of the most aggressive oxidants formed from Fenton reactions. In this regard, $S$. tuberculata extracts significantly inhibited the oxidation of deoxyribose in low concentrations (Table 6). Overall, hydroethanolic extracts showed stronger inhibition activity than aqueous extracts.

Analyses of lipid peroxidation from egg yolks (Figure $2 \mathrm{~A}$ and $\mathrm{B}$ ) showed that both extracts of $S$. tuberculata inhibited lipid peroxidation. Hydroethanolic extracts exhibited significant inhibition from 0.015 and $0.03 \mathrm{mg} / \mathrm{mL}$ for leaves and roots, respectively $(P \leqslant 0.05)$. Aqueous extracts showed significance from $0.15 \mathrm{mg} / \mathrm{mL}$ for both parts of plants. Comparing leaves and roots, the leaves had greater antioxidant activity than roots.

Figure $2 C$ and $D$ shows the effects of $S$. tuberculata extracts on lipid peroxidation caused by $\mathrm{Fe}^{+2}$ in rat brain homogenates. The iron concentration tested $(0.01 \mathrm{mM})$ induced a significant oxidative damage $(P \leqslant 0.05)$. We observed that hydroethanolic extracts from leaves and roots presented a significant decrease on TBARS formation $(P \leqslant 0.05)$ from 0.015 and $0.03 \mathrm{mg} / \mathrm{mL}$ concentrations, respectively. Aqueous extracts showed a significant reducing effect from 0.03 and $0.3 \mathrm{mg} / \mathrm{mL}$ concentrations for leaves and roots, respectively.

In liver tissue, all extracts of $S$. tuberculata inhibited TBARS production (Figure 2E and F). However, the hydroethanolic extracts exerted a more pronounced effect. At concentrations of 0.03 and $0.3 \mathrm{mg} / \mathrm{mL}$, hydroethanolic extracts of leaves and roots inhibited lipid peroxidation to almost baseline levels.

\section{Discussion}

The present study describes an investigation about the medicinal plant S. tuberculata from Brazilian Pampa biome. We evaluated the dry residue and the concentration of the major compound (20E) with different extraction techniques applied on $S$. tuberculata. The data were used to select the extracts to be applied in toxicity and antioxidant assays. This method has a central role in obtaining products with constant composition and reproducible biological properties.

Considering the parameters evaluated for leaves and roots, percolation was the most effective technique. Results showed that percolation method improved the dry residue and $20 \mathrm{E}$ concentration. This finding may be related to the technique's exhaustive extraction and solvent renewal. Differently from maceration and reflux, in percolation the solvent remains $1 \mathrm{~h}$ in contact with the sample and then elutes through the column more than once with fresh solvent. Moreover, percolation methodology does not involve heating, an important aspect taking into account the thermolability of some phytoconstituents.

Our chromatographic analysis confirmed $20 \mathrm{E}$ as the main metabolite in leaves and roots. Moreover, a kaempferol derivative was detected only in leaves. This finding is in accordance with a previous phytochemical study by our group (9). In addition, we observed the presence of more metabolites in leaves than in roots. This result may be partially explained by the sunlight influence on biosynthesis of some compounds such as flavonoids (27).

The major identified compound (20E) belongs to the ecdysteroids class. It has a steroidal nucleus and a polyhydroxylated chain (Figure 3). Ecdysteroids or "phytoecdysteroids" are the plant analogues of insect growth hormones. Their function in plants is unclear; however, they may be involved in the deterrence of invertebrate predators by acting as antifeed-systems, or yet by interfering in the ingestion of phytophagous insects (16). In mammals, $20 \mathrm{E}$ has demonstrated therapeutic properties including memory improvement, reduction of lipid storage and anabolic effects (28-30).

The predictive Ames test used here is performed worldwide as an initial screening to determine genotoxic 

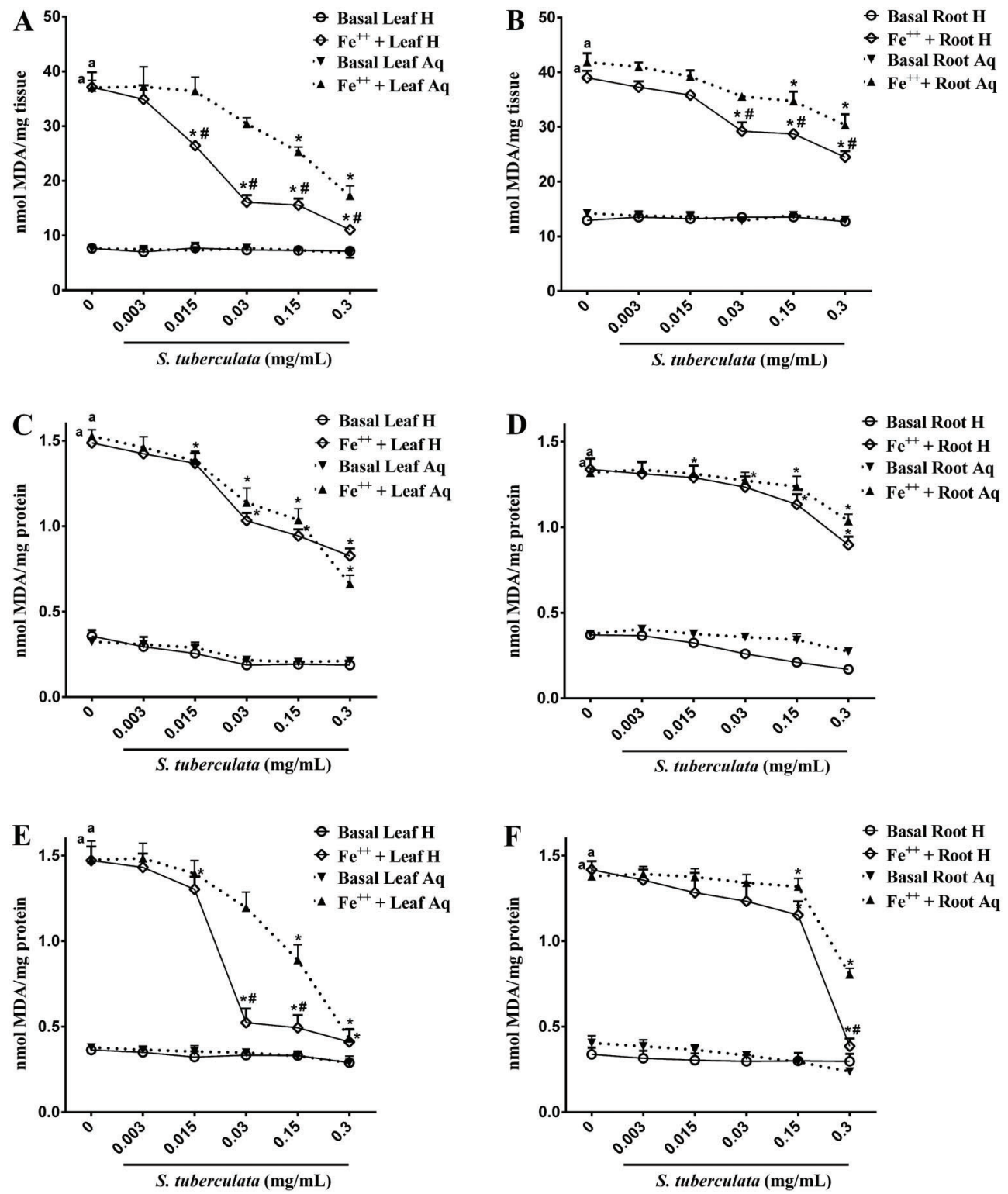

Figure 2. Effects of $S$. tuberculata extracts on TBARS production in egg yolk lipids $(A, B)$, brain $(C, D)$ and liver $(E, F)$ of rats. Hydroethanolic leaf extract (Leaf H), aqueous leaf extract (Leaf Aq), hydroethanolic root extract (Root $H)$, and aqueous root extract (Root $\mathrm{Aq})$ were evaluated. Results are reported as nmol of MDA per mg of tissue $(A, B)$ or $\mathrm{mg}$ of protein $(C-F)$ for $(\mathrm{n}=3)$. ${ }^{\text {a }} \mathrm{P} \leqslant 0.05$ compared to basal not induced (i.e., zero concentration); ${ }^{*} \mathrm{P} \leqslant 0.05$ compared to basal in the same group (i.e., zero concentration); \#P $\leqslant 0.05$ compared to the same concentration of the other extracts evaluated (two-way ANOVA with the Tukey's post tests).

properties of new chemical entities to be used by the pharmaceutical industry. It is a quick test, based on bacterial reverse mutation performed on various bacterial strains. The genotoxicity predicted by the Ames Test is based on an iterative model built using structural toxic fragments from a database as descriptors. 20E showed a low probability for genotoxicity $(10 \%)$.

The endocrine disruptor test is associated with the binding of compounds to alpha estrogen receptor, which may be linked to reproductive toxicity and cancers (31). The 20E was classified as binder/non-binder, due to their relative binding affinities (RBA) compared to a reference ligand in the ACD/Labs database (17). Two cut-offs were used: LogRBA $\geqslant 3$ ("general binding"), and LogRBA >0 ("strong binding") and $20 \mathrm{E}$ presented a $1 \%$ probability to be a LogRBA $\geqslant 3$. This measurement is important since the $20 \mathrm{E}$ has a steroidal structure and may interact with in vivo hormonal receptors. 
<smiles>CC(C)(O)CCC(O)[C@@](C)(O)[C@H]1CC[C@]2(O)C3=CC(=O)[C@@H]4C[C@@H](O)[C@@H](O)C[C@]4(C)[C@H]3CC[C@]12C</smiles>

Figure 3. Representation of 20-hydroxyecdysone molecular structure $\left(\mathrm{C}_{27} \mathrm{H}_{44} \mathrm{O}_{7}\right)$. PubChem CID: 5459840 .

Another assessed toxic effect was the hERG inhibition, which is an ion channel that, when inhibited, is related to cardiovascular damage (32). It is essential to investigate any chemical entity for this potential cardiotoxic effect. A large number of drugs have been withdrawn from clinical trials or from the market due to the fatalities associated to hERG inhibition. The hERG predictive inhibition for $20 \mathrm{E}$ was $3 \%$. Similarly, irritant properties related to skin and eye tissues were evaluated, and nontoxic results were found. The low toxic probability of $20 \mathrm{E}$, may be in part due to the absence of hazardous fragments (predictive data), which are known toxic agents.

The $A$. salina toxicity assay is practical, inexpensive, simple, reliable and an important tool in routine plant toxicity screening. Our data showed very low toxicity of hydroethanolic and aqueous extracts from leaves and roots. As the test implies the presence of cytotoxic constituents, as initial screening, our results indicate that aqueous extracts used as folk medicine have a low risk of acute toxicity. However, further studies are necessary to establish the toxicological endpoints at systemic level.

Since this work proposed to investigate the antioxidant potential of $S$. tuberculata extracts, we evaluated the overall potential of its major compound to be qualified as a nutraceuticals product and, therefore, be available in the market. Thus, the compound $20 \mathrm{E}$ was subjected to an in silico screening to evaluate its theoretical drug-likeness and drug-score in comparison with antioxidants references, ascorbic acid and $\alpha$-tocopherol. The positive values of drug-likeness indicated that $20 \mathrm{E}$ contains fragments as good as the references. These results increase the possibility of establishing the therapeutic actions of these fragments, known as pharmacophores, and of this compound becoming a possible nutraceuticals product.

The assessment of antioxidant activity was applied for $40 \%$ (leaves) and $70 \%$ (roots) hydroethanolic extracts, obtained by percolation technique. It is important to emphasize that the best extractive system was defined observing the results of all evaluated parameters, and trying to maintain the stability of metabolites. Aqueous infusions were assayed, with the purpose of evaluating the method usually employed by the population in preparing home remedies.

The antioxidant capacity of an extract or compound can be analyzed by several assays with different mechanisms (33). Generally, the chemical reaction involved in antioxidant in vitro assays fall into two categories: hydrogen atom transfer (HAT) assays, which use a competitive reaction between an antioxidant and a substrate, where both compete for peroxyl radicals thermally generated, and single electron transfer $(E T)$ reaction assays, that measure the potential of an antioxidant to reduce an oxidant, which changes color when reduced. All these elements, advantages and limitations, need to be considered when evaluating and selecting a potential antioxidant.

In view of the above comments, we used six different methods to evaluate the antioxidant capacity of $S$. tuberculata extracts: $\mathrm{DPPH}^{\bullet}, \mathrm{ABTS}^{\bullet+}, \mathrm{NO}$ and FRAP based in ET assays, and deoxyribose and TBARS, which are based in HAT. Results indicated that both leaves and roots extracts, could act by ET and HAT mechanisms. Moreover, data showed that hydroethanolic extracts present a better antioxidant potential than aqueous extracts. This fact may be related with a greater extraction ability of ethanol than water alone. Yea et al. (34), evaluating the effect of different solvents on phenolic content, found a higher extraction capacity in aqueous alcohols than water.

We also observed that leaves presented higher scavenger properties than roots. This finding probably occurred due to the diversity of phytoconstituents present in leaves. In fact, our analysis identified a kaempferol derivative detected only in the leaves. In this context, phenolic compounds are known for its antioxidant properties, such as free radical scavenging and chelation of metal ions. Therefore, the presence of phenolic compounds may explain the notable antioxidant activity in leaves. Moreover, concomitant occurrence of phenols and ecdysteroids may improve antioxidant potential by synergistic effects (35). However, it is not possible to know precisely if ecdysteroid class compounds exert antioxidant effects.

Our results for $\mathrm{DPPH}^{\bullet}, \mathrm{ABTS}^{\bullet+}$, FRAP and NO assays are agreement with Pawar et al. (36) and Shah et al. (37), who reported a great antioxidant activity for $S$. cordifolia and S. cordata. It should be noted that the effect of S. tuberculata detected with Griess reaction may be due to scavenger activity of extracts for nitrogen derivative species, i.e., $\mathrm{NO}_{2}$, $\mathrm{N}_{2} \mathrm{O}_{3}, \mathrm{~N}_{2} \mathrm{O}_{4}$, peroxynitrite $\left(\mathrm{ONOO}^{-}\right.$) or even for different redox forms, such as nitrosonium $\left(\mathrm{NO}^{+}\right)$and nitroxyl anion $\left(\mathrm{NO}^{-}\right)$generated or interconverted from nitric oxide under physiological conditions. Therefore, the antioxidant activity is an important property, since it prevents the formation of deleterious oxidants that can react with biological molecules, particularly oxidizing iron/sulfur centers, zinc fingers, and protein thiols, which plays a relevant role in cardiovascular and neurological diseases $(23,38)$. 
In this context, it is known that iron plays a significant role in noxious oxygen species production. Iron initiates a chain of reactions leading to lipid peroxidation and consequent cellular damage. Our data showed a protective effect of all extracts of $S$. tuberculata against oxidative damage by deoxyribose and TBARS assays.

One possible protection mechanism against lipid peroxidation damage may be related to $\mathrm{Fe}^{2+}$ chelating activity. In this case, the extract binds to metal preventing it to interact with $\mathrm{H}_{2} \mathrm{O}_{2}$ avoiding hydroxyl radical $\left(\mathrm{OH}^{\circ}\right)$ generation and consequently the damage. In other words, chelating compounds may decrease metal bioavailability inhibiting its participation in $\mathrm{OH}^{\bullet}$ generation by the Fenton reaction $(39,40)$. S. tuberculata extracts presented a significant $\mathrm{Fe}^{2+}$ chelating activity (data not shown), which may support the observed decrease in lipid peroxidation. Another possibility would be $\mathrm{OH}^{\bullet}$ neutralization by atom transfer. Thus, considering the $S$. tuberculata scavenger

\section{References}

1. Thounaojam MC, Jadeja RN, Dandekar DS, Devkar RV, Ramachandran AV. Sida rhomboidea.Roxb extract alleviates pathophysiological changes in experimental in vivo and in vitro models of high fat diet/fatty acid induced nonalcoholic steatohepatitis. Exp Toxicol Pathol 2012; 64: 217-224, doi: 10.1016/j.etp.2010.08.009.

2. Dinda B, Das N, Dinda S, Dinda M, SilSarma I. The genus Sida $L$. - a traditional medicine: Its ethnopharmacological, phytochemical and pharmacological data for commercial exploitation in herbal drugs industry. J Ethnopharmacol 2015; 176: 135-176, doi: 10.1016/j.jep.2015.10.027.

3. Franzotti EM, Santos CV, Rodrigues HM, Mourao RH, Andrade MR, Antoniolli AR. Anti-inflammatory, analgesic activity and acute toxicity of Sida cordifolia L. (Malva-branca). J Ethnopharmacol 2000; 72: 273-277, doi: 10.1016/S03788741(00)00205-1.

4. Silva RL, Melo GB, Melo VA, Antoniolli AR, Michellone PR, Zucoloto S, et al. Effect of the aqueous extract of Sida cordifolia on liver regeneration after partial hepatectomy. Acta Cir Bras 2006; 21 (Suppl 1): 37-39, doi: 10.1590/ S0102-86502006000700009.

5. Khurana N, Gajbhiye A. Ameliorative effect of Sida cordifolia in rotenone induced oxidative stress model of Parkinson's disease. Neurotoxicology 2013; 39: 57-64, doi: 10.1016/ j.neuro.2013.08.005.

6. Sreedevi CD, Latha PG, Ancy P, Suja SR, Shyamal S, Shine VJ, et al. Hepatoprotective studies on Sida acuta Burm. f. J Ethnopharmacol 2009; 124: 171-175, doi: 10.1016/ j.jep.2009.04.055.

7. Thounaojam MC, Jadeja RN, Ansarullah, Shah JD, Patel DK, Salunke SP, et al. Cardioprotective effect of Sida rhomboidea. Roxb extract against isoproterenol induced myocardial necrosis in rats. Exp Toxicol Pathol 2011; 63: 351-356, doi: 10.1016/j.etp.2010.02.010.

8. Kumawat RK, Kumar S, Sharma S. Evaluation of analgesic activity of various extracts of Sida tiagii Bhandari. Acta Pol Pharm 2012; 69: 1103-1109. effects on $\mathrm{DPPH}^{\bullet}$ and $\mathrm{ABTS}{ }^{\bullet}$ radicals, we may suggest that the $\mathrm{OH}^{\bullet}$ radical scavenging potential of extracts interfered in the oxidation process.

In conclusion, S. tuberculata presented different classes of metabolites, predominantly phytoecdysteroids, which, together with polyphenols, may be involved with antioxidant activity. In addition, 20E showed an in silico low risk, and crude extracts had very low cytotoxicity against $A$. salina larvae. Thus, due the medicinal potential revealed by $S$. tuberculata, it is important to conduct further in vivo studies, as well as to consider $20 \mathrm{E}$ as a promising molecule for further investigations on oxidative stress from a nutraceutical source.

\section{Acknowledgments}

The authors are grateful to CAPES (Brasília, Brazil) and PBDA-Unipampa (Uruguaiana, Brazil) for financial support.

9. da Rosa HS, de Camargo V, Camargo G, Garcia CV, Fuentefria AM, Mendez AS. Ecdysteroids in Sida tuberculata R.E. Fries (Malvaceae): chemical composition by LC-ESI-MS and selective anti-Candida krusei activity. Food Chem 2015; 182: 193-199, doi: 10.1016/j.foodchem.2015.02.144.

10. Dinan L, Bourne P, Whiting P. Phytoecdysteroid profiles in seeds of Sida spp. (Malvaceae). Phytochem Anal 2001; 12: 110-119, doi: 10.1002/pca.566.

11. Silveira AL, Gomes MAS, Silva Filho RN, Santos MRV, Medeiros IA, Barbosa Filho JM. Evaluation of the cardiovascular effects of vasicine, an alkaloid isolated from the leaves of Sida cordifolia L. (Malvaceae). Braz J Pharmacog 2003; 3 (Suppl 2): 37.

12. Sutradhar RK, Rahman AKMR, Ahmad MU, Bachar CS. Bioactive flavones of Sida cordifolia. Phytochem Lett 2008; 1: 179-182, doi: 10.1016/j.phytol.2008.09.004.

13. Wang YH, Avula B, Jadhav AN, Smillie TJ, Khan IA. Structural characterization and identification of ecdysteroids from Sida rhombifolia L. in positive electrospray ionization by tandem mass spectrometry. Rapid Commun Mass Spectrom 2008; 22: 2413-2422, doi: 10.1002/rcm.3625.

14. Darwish FM, Reinecke MG. Ecdysteroids and other constituents from Sida spinosa L. Phytochemistry 2003; 62: 1179-1184, doi: 10.1590/S0102-695X2003000400012.

15. Dinan L, Savchenko T, Whiting P. On the distribution of phytoecdysteroids in plants. Cell Mol Life Sci 2001; 58: 1121-1132, doi: 10.1007/PL00000926.

16. Anonymous. Brazilian pharmacopoeia. Vol. 2. 5th edn. Brasilia: Anvisa; 2010.

17. ACD/Labs team [Online]. https://ilab.acdlabs.com/iLab2/. Accessed October, 2015.

18. Osiris property explorer [Online]. http://www.organicchemistry. org/prog/peo/. Accessed October, 2015.

19. Meyer BN, Ferrigni NR, Putnam JE, Jacobsen LB, Nichols $D E$, McLaughlin JL. Brine shrimp: a convenient general bioassay for active plant constituents. Planta Med 1982; 45: 31-34, doi: 10.1055/s-2007-971236. 
20. Choi CW, Kim SC, Hwang SS, Choi BK, Ahn HJ, Lee MY, et al. Antioxidant activity and free radical scavenging capacity between Korean medicinal plants and flavonoids by assay-guided comparison. Plant Sci 2002; 163: 1161-1168, doi: 10.1016/S0168-9452(02)00332-1.

21. Re R, Pellegrini N, Proteggente A, Pannala A, Yang M, Rice-Evans C. Antioxidant activity applying an improved ABTS radical cation decolorization assay. Free Radic Biol Med 1999; 26: 1231-1237, doi: 10.1016/S0891-5849(98)00315-3.

22. Pulido R, Bravo L, Saura-Calixto F. Antioxidant activity of dietary polyphenols as determined by a modified ferric reducing/antioxidant power assay. J Agric Food Chem 2000; 48: 3396-3402, doi: 10.1021/jf9913458.

23. Marcocci L, Packer L, Droy-Lefaix MT, Sekaki A, GardèsAlbert M. Antioxidant action of Ginkgo biloba extract EGb 761. Methods Enzymol 1994; 234: 462-475, doi: 10.1016/ 0076-6879(94)34117-6.

24. Puntel RL, Nogueira CW, Rocha JB. Krebs cycle intermediates modulate thiobarbituric acid reactive species (TBARS) production in rat brain in vitro. Neurochem Res 2005; 30: 225-235, doi: 10.1007/s11064-004-2445-7.

25. Hassan W, Ibrahim M, Nogueira CW, Ahmed M, Rocha JB. Effects of acidosis and $\mathrm{Fe}$ (II) on lipid peroxidation in phospholipid extract: Comparative effect of diphenyl diselenide and ebselen. Environ Toxicol Pharmacol 2009; 28: 152-154, doi: 10.1016/j.etap.2009.02.004

26. Ohkawa $\mathrm{H}$, Ohishi $\mathrm{N}$, Yagi K. Assay for lipid peroxides in animal tissues by thiobarbituric acid reaction. Anal Biochem 1979; 95: 351-358, doi: 10.1016/0003-2697(79)90738-3.

27. Muzitano MF, Bergonzi MC, De Melo GO, Lage CL, Bilia AR, Vincieri FF, et al. Influence of cultivation conditions, season of collection and extraction method on the content of antileishmanial flavonoids from Kalanchoe pinnata. J Ethnopharmacol 2011; 133: 132-137, doi: 10.1016/j.jep.2010.09.020.

28. Xia X, Zhang Q, Liu R, Wang Z, Tang N, Liu F, et al. Effects of 20-hydroxyecdysone on improving memory deficits in streptozotocin-induced type 1 diabetes mellitus in rat. Eur $J$ Pharmacol 2014; 740: 45-52, doi: 10.1016/j.ejphar.2014. 06.026.

29. Foucault AS, Even P, Lafont R, Dioh W, Veillet S, Tome D, et al. Quinoa extract enriched in 20-hydroxyecdysone affects energy homeostasis and intestinal fat absorption in mice fed a high-fat diet. Physiol Behav 2014; 128: 226-231, doi: 10.1016/j.physbeh.2014.02.002.
30. Parr MK, Botre F, Nass A, Hengevoss J, Diel P, Wolber G. Ecdysteroids: A novel class of anabolic agents? Biol Sport 2015; 32: 169-173, doi: 10.5604/20831862.1144420.

31. Ali S, Coombes RC. Estrogen receptor alpha in human breast cancer: occurrence and significance. J Mammary Gland Biol Neoplasia 2000; 5: 271-281, doi: 10.1023/ A:1009594727358.

32. Thomas D, Karle CA, Kiehn J. The cardiac hERG/ $\mathrm{IKr}$ potassium channel as pharmacological target: structure, function, regulation, and clinical applications. Curr Pharm Des 2006; 12: 2271-2283, doi: 10.2174/138161206777585102.

33. Shahidi F, Zhong Y. Measurement of antioxidant activity. $J$ Funct Food 2015; 18: 757-781, doi: 10.1016/j.jff.2015. 01.047.

34. Yea F, Lianga Q, Lic H, Zhaoa G. Solvent effects on phenolic content, composition, and antioxidantactivity of extracts from florets of sunflower (Helianthus annuus L.). Ind Crop Prod 2015; 76: 574-581, doi: 10.1016/j.indcrop.2015.07.063.

35. Wang F, Zhao S, Li F, Zhang B, Qu Y, Sun T, et al. Investigation of antioxidant interactions between Radix astragali and Cimicifuga foetida and identification of synergistic antioxidant compounds. PLoS One 2014; 9: e87221, doi: 10.1371/journal.pone.0087221.

36. Pawar RS, Jain A, Sharma P, Chaurasiya PK, Singour PK. In vitro studies on Sida cordifolia Linn for anthelmintic and antioxidant properties. Chinese Med 2011; 2: 47-52, doi: 10.4236/cm.2011.22009.

37. Shah NA, Khan MR, Ahmad B, Noureen F, Rashid U, Khan RA. Investigation on flavonoid composition and anti free radical potential of Sida cordata. BMC Complement Altern Med 2013; 13: 276, doi: 10.1186/1472-6882-13-276.

38. Pacher P, Beckman JS, Liaudet L. Nitric oxide and peroxynitrite in health and disease. Physiol Rev 2007; 87: 315-424, doi: 10.1152/physrev.00029.2006.

39. Macakova K, Mladenka P, Filipsky T, Riha M, Jahodar L, Trejtnar $F$, et al. Iron reduction potentiates hydroxyl radical formation only in flavonols. Food Chem 2012; 135: 2584-2592, doi: 10.1016/j.foodchem.2012.06.107.

40. Salgueiro AC, Leal CQ, Bianchini MC, Prado IO, Mendez AS, Puntel RL, et al. The influence of Bauhinia forficata Link subsp. pruinosa tea on lipid peroxidation and non-protein $\mathrm{SH}$ groups in human erythrocytes exposed to high glucose concentrations. J Ethnopharmacol 2013; 148: 81-87, doi: 10.1016/ j.jep.2013.03.070. 